\title{
DEPARTMENT OF THE HISTORY OF MEDICINE, MAYO GRADUATE SCHOOL OF MEDICINE
}

A new Department of the History of Medicine has been established in the Mayo Graduate School of Medicine, a part of the University of Minnesota Graduate School, at Rochester, Minnesota. The head of the department is Dr. Charles G. Roland, chairman of the Department of Biomedical Communications of the Mayo Clinic, who will have the grade of associate professor.

Dr. Roland was graduated from the University of Toronto in 1954, and from the University of Manitoba Faculty of Medicine in 1958. He practised medicine in Ontario from 1959 to 1964; in 1964 he was named senior editor of the Journal of the American Medical Association. Since 1969 he has been chairman of the Department of Biomedical Communications of the Mayo Clinic, a post he will continue to occupy.

\section{INSTITUTE OF HISTORY OF MEDICINE AND MEDICAL RESEARCH, TUGHLAQABAD, NEW DELHI 44, INDIA}

The Museum and the Library of the Institute of History of Medicine and Medical Research, New Delhi, a multi-faceted project, which forms the first phase of the Institute's plans, were inaugurated recently by the Prime Minister of India, Mrs. Indira Gandhi.

The need of an Institute of history of medicine in India cannot be over-emphasized as India is the meeting place of various systems of medicine and has a wealth of untapped research material which demands proper study. In order to meet this requirement a scheme for the establishment of an Institute of history of medicine and medical research in New Delhi was drawn up and subjected to scrutiny and revision several times. In November 1962 the foundation stone of the Institute was laid by the late Mr. Jawaharlal Nehru, first Prime Minister of India. This Institute which has been established with the following objectives fulfils a long felt necessity: (1) to promote medical education and research; (2) to study and promote the knowledge of history of medicine and to undertake research thereof; (3) to undertake scientific appraisal of the principles and practices of the various systems of medicine; and (4) to collaborate in kindred activities with other national or international organizations with similar objects.

The Museum comprises a large number of paintings on the theme of medicine by eminent artists, statues, busts, replicas, models of surgical instruments and chemical apparatus, drugs, a variety of jars and bottles, placards, maps, charts, drawings, photographs, etc. A stroll through the Museum offers one a vivid portrayal of the development of medicine through the ages. The Library has on its shelves several thousand printed volumes on medicine, history of medicine, pharmacy, science and technology in many important languages of the world, and several hundred medical manuscripts. 